\title{
THE INFLUENCE OF PSYCHOLOGICAL PREPARATION ON FOOTBALL AND KARATE TRAINING IN PRIMARY SCHOOL PUPILS
}

\author{
Margaritova V. \\ Plovdiv University "Paisii Hilendarski" \\ Reviewed by: Prof. A. Klisarova, MD, PhD, D.Sci
}

\begin{abstract}
Through psychological preparation physical readiness is formed. Psychological preparedness is a complex phenomena which is a reflection of the level of preparation of an individual for action in different situations. For many coaches training is the process of physical preparation, but the end result is also heavily influenced by psychological factors. In the present work we look at the influence of psychological preparation in the training of football and karate with pupils of primary school age.
\end{abstract}

Keywords: Psychological preparation, psychological readiness, training

All human action requires a certain amount of physical and psychological preparation, and in sport this is even more true. Sports preparation is a whole system of inter-dependent and mutually conditional aspects physical, technical, tactical, and psychological. Neglect of one element in the system has a negative effect on results. Psychological preparation is an important part of the many faceted and complex preparation in the educational-training process. Many scholars regard psychological preparation simply as a test of separate psychological qualities or process', but by doing so they fail to fathom the full essence of the phenomena but only aspects of it. Psychological preparation is an important part of the many faceted and complex preparation of athletes and teams.

According to T. Yancheva (1977) psychological preparation is a prerequisite and a result of the educational-training process: a prerequisite because the effectiveness and quality of the sporting performance and results depend on the level of physical preparation, because the sporting level reached has a psychological impact. Indeed, psychological preparation may be even regarded as the basis for the development of physical preparation.

Vasilev (1987) separates psychological preparation into four categories: general, specialized, collective and specific. In his opinion psychological preparation forms the necessary capacities, will and emotional qualities.

Physical preparation is the second sub-structure of psychological preparation. Different views on physical preparation veil its essence.

\footnotetext{
Address for correspondence:

Valentina Margaritova, Plovdiv University "Paisii Hilendarski", 24,

Tsar Asen Str., 4000 Plovdiv, BULGARIA

e-mail: valia_margaritova@abv.bg
}

For many authors physical preparation is a sports-education process for the many aspects of physical development, for controlling the motor functions and for achieving a certain level of physical capability (Kr. Rachev, 1987). In our opinion physical preparation is a condition and a process: on one hand is the manifestation of physical development, physical ability and the functional condition of the individual; on the other hand the process directed towards reaching a certain level. Therefore physical preparation is geared towards creating an adequate level of physical preparation which consists of physical qualities, condition and process'. Practical action is realized through physical preparation. Psychological preparation facilitates physical preparation.

In the activity of physical exertion the concept of psycho-physical is used as a unitary combination of physical and psychological. In the rich theory of personality and human activity the term psycho-physical has also emerged. This development has become possible with the emergence of new mathematical methods for measuring and modulating the psychological and motor phenomena and the discovery of the determinants in their indicators. Due to the basis attained by science, conditions have been created for the discovery of new aspects of the concept of psycho-physical. According to D. Kare (1973) sporting accomplishments are the result, not only of theoretical and technical preparation, but also of the psychological preparation of the competitors. In the process of self-realization psychological preparation plays a key role. In the modern hectic and changing times the contents of the human activity area also changing. Mobility in the modern individual is lessening, physical activity giving way to mental.

The aim of psychological preparation is formation of psycho-physical preparedness. If we proceed from the 
assumption of the unity of internal and external activity in the structure of the activity we define psycho-physical readiness as - an integral condition which determines the unity of physical and psychological preparedness in the structure of the individuals activity during his adaptation to changing conditions in his environment for a certain period of time.

Psycho-physical preparedness is a complex phenomena which reflects the readiness of an individual to act in different situations. Through it one may control the actions and behavior of an individual and to diagnose his level of preparation to accomplish given aims and tasks.

The structure of psycho-physical preparedness is confined by models, including the correlation dependence between separate psychological structures, factors, elements and components. With the increasing power of inter-relations between constructive factors, elements and components of the structure of psycho-physical preparedness an adequate readiness is formed and in the case of a reduction - an inadequate one. D. Kaikov (1990) investigated the complex system of steps of adequate preparedness: standard, raised, high and highly elevated, and inadequate raised, low, demobilizing.

The object of the research is to pinpoint the effects of the models created by us on primary coaching in football and karate on the psychological preparedness of pupils at primary school.

The study encompassed 127 pupils of primary school age, who were separated into 5 groups: 3 experimental and 2 control.

On I EG (experimental group) - football, II EG -karate, boys and III EG - karate, girls, the model constructed by us was put into effect. I KG (control group) girls and II KG boys trained by standard methods in different sporting sections. For concrete comparison data on the differences constituted we used t-criteria of the student with suitable guaranteed probability. Analysis of the indicators characterizing the dynamics of the development of psychological qualities was carried out on the basis of quantitative characteristics of the various indicators reflected in the tables. The dynamics of the development of psychological qualities in the three experimental groups will be studied through the following statistical parameters: average mathematical value of variation, standard divergence, co-efficient of variation, reliability.

The test, through which the psychological preparation of the children training football and karate is measured, is temporal awareness. The higher the awareness the children have of the passage of time, the higher and more adequate is their level of preparation.

The research illustrates that as a result of training certain changes in temporal awareness occur. (Table 1).

In the given time of 17 seconds, research on the first test shows time passes quicker by $3.2 \mathrm{sec}$. in KG I, $2.8 \mathrm{sec}$. in KG II and $2.9 \mathrm{sec}$. in KG III, in comparison with the given control time. In the second test the accuracy in defining the time taken improves: with a difference of $1.9 \mathrm{sec}$. in CG I, $1.5 \mathrm{sec}$. in KG II, $0.2 \mathrm{sec}$. in EG I, $0.9 \mathrm{sec}$. in EG II, and 0.8 sec. in EG III. This difference is due to the special methods used in the training of the two sport types.

Table 1. Indicators in the test for temporal awareness

\begin{tabular}{|c|c|c|c|c|c|c|c|c|}
\hline \multirow{2}{*}{$\begin{array}{l}\text { Research } \\
\text { Groups }\end{array}$} & \multicolumn{3}{|c|}{ First Test } & \multicolumn{3}{|c|}{ Second Test } & \multirow{2}{*}{ Difference } & \multirow{2}{*}{$\begin{array}{c}\text { Reliability } \\
(\%)\end{array}$} \\
\hline & $\bar{x}$ & $\mathrm{~s}$ & $\begin{array}{c}\mathrm{V} \\
(\%)\end{array}$ & $\bar{x}$ & $\mathrm{~s}$ & $\begin{array}{c}\mathrm{V} \\
(\%)\end{array}$ & & \\
\hline I CG & 20,2 & 5,0 & 25 & 18,9 & 3,8 & 20 & 1,3 & 98 \\
\hline II CG & 19,6 & 5,1 & 26 & 18,5 & 3,7 & 20 & 1,1 & 98 \\
\hline IEG & 19,5 & 4,0 & 20,5 & 16,8 & 3,5 & 21 & 2,7 & 99 \\
\hline II EG & 19,8 & 4,2 & 21 & 17,9 & 3,1 & 17 & 1,9 & 99 \\
\hline III EG & 19,9 & 4,5 & 23 & 17,8 & 2,9 & 16 & 2,1 & 99 \\
\hline
\end{tabular}

The improvement in temporal awareness is one of the basic factors indicating the level of psychological preparation and the ability of the children to regulate internal stress in the process of football and karate training.

From the study of the results of temporal awareness we can surmise that, as a result of the effects of the model, accuracy is improved as an element of psychological preparation and a factor of its improvement and creation of an adequate level of psychological preparation.

In order to form adequate psychological preparation, perception also plays a key role. Audience perception is one of the main factors which define the level of preparation for action in various situations. In table 2 clarity level and latent time are presented.

\begin{tabular}{|c|c|c|c|c|c|c|c|c|}
\hline \multirow{2}{*}{ Indicator } & \multirow{2}{*}{ Group } & \multicolumn{3}{|c|}{ First Research } & \multicolumn{3}{|c|}{$\begin{array}{c}\text { Second } \\
\text { Research }\end{array}$} & \multirow{2}{*}{$\begin{array}{c}\text { Reliability } \\
\text { P } \\
(\%)\end{array}$} \\
\hline & & $\bar{x}$ & $s$ & $\begin{array}{c}\mathrm{V} \\
(\%)\end{array}$ & $\bar{x}$ & $s$ & $\begin{array}{c}\mathrm{V} \\
(\%)\end{array}$ & \\
\hline \multirow{5}{*}{$\begin{array}{c}\text { Clarity } \\
\text { level }\end{array}$} & I CG & 3,40 & 0,58 & 17 & 3,75 & 0,52 & 14 & 99 \\
\hline & II CG & 3,50 & 0,54 & 15 & 3,75 & 0,54 & 14 & 98 \\
\hline & I CG & 3,50 & 0,50 & 14 & 4,00 & 0,49 & 12 & 99 \\
\hline & II CG & 3,25 & 0,52 & 16 & 4,25 & 0,48 & 11 & 99 \\
\hline & III CG & 3,75 & 0,48 & 13 & 4,25 & 0,42 & 10 & 99 \\
\hline \multirow{5}{*}{$\begin{array}{l}\text { Latent } \\
\text { time }\end{array}$} & I CG & 4,5 & 0,69 & 15 & 4,0 & 0,53 & 13 & 98 \\
\hline & II CG & 4,9 & 0,62 & 13 & 4,5 & 0,66 & 15 & 99 \\
\hline & I EG & 4,8 & 0,55 & 11 & 3,7 & 0,52 & 14 & 99 \\
\hline & II EG & 4,3 & 0,53 & 12 & 3,5 & 0,50 & 14 & 99 \\
\hline & III EG & 4,4 & 0,50 & 11 & 3,5 & 0,49 & 14 & 99 \\
\hline
\end{tabular}

From table 2 it is obvious that the level of clarity in the control groups has increased slightly: 0.35 for CG I and 0.25 for CG II. The improvement is greater among the experimental groups: 0.5 in EG's I and II and 1.00 in EG II. The latent time has also improved significantly: in CG I lessening by $0.5 \mathrm{sec} ., 0.4 \mathrm{sec}$. in CG II, $0.9 \mathrm{sec}$. in EG I, 0.8 
sec. in EG II, and 0.9 sec. in EG III. These changes are a basic indicator through which one can adjudicate an improvement in the psychological preparation structure. One may conclude that a substantial change in psychological awareness is to be observed in the subjects studied by us who underwent football and karate training. Furthermore, the latent time for forming the image has a significant effect on the clarity of the image $(r=-0,62)$ (fig. 1). This dependence is significant for the regulation and optimization of psychological preparation, and thus for the individuals actions: for heightening the clarity of perception and imagination it is necessary during training to shorten the time for forming perception.

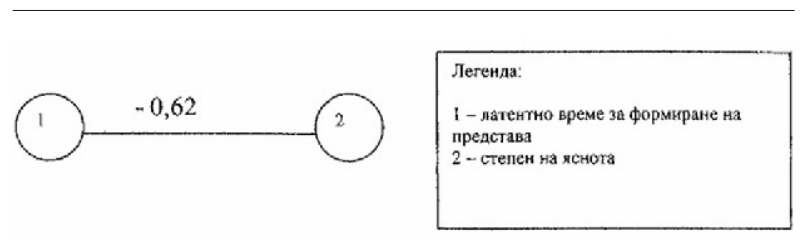

Fig. 1. Inter-dependence in the structure of perception KEY: Latent time for forming perception; Level of clarity

\section{CONCLUSIONS}

1. Football and karate are activities linked to a high level of concentration of physical and psychological effort for quick and accurate action, determined by adequate psychological preparation.
2. The applied models for psycho-physical preparation have a significant effect on the formation of psychological qualities, improving the value of the indicators and links between them. In karate the model has a greater effect on the accuracy of psychological activity and in football - on speed.

\section{RECOMMENDATIONS}

1. To research the effectiveness of the model on students in higher classes.

2. Tested models to be applied in the football and karate training systems.

\section{BIBLIOGRAPHY}

1. Василев, В. За съдържанието и структурата на психическата подготовка. А. Преглед. С., 1987

2. Кайков, Д. Психофизическа подготовка за действие в екстремални ситуации. С., 1983

3. Кайков, Д. Психофизическа подготовка за защита на отечеството. С., 1990

4. Рачев, К. ТМФВ. С., 1987

5. Харе, Д. Учение за тренировката.. Translation from German. C., 1973

6. Янчева, Т. Психологическо осигуряване на спортната подготовка. С., 1997 